\title{
PARP-1 inhibition sensitizes temozolomide-treated glioblastoma cell lines and decreases drug resistance independent of MGMT activity and PTEN proficiency
}

\author{
ANA P. MONTALDI ${ }^{1}$, SARAH C.G. LIMA ${ }^{1}$, PAULO R.D.V. GODOY ${ }^{1}$, \\ DANILO J. XAVIER ${ }^{1}$ and ELZA T. SAKAMOTO-HOJO ${ }^{1,2}$
}

\begin{abstract}
${ }^{1}$ Department of Biology, Faculty of Philosophy, Sciences and Letters at Ribeirão Preto, University of São Paulo (USP), Ribeirão Preto, São Paulo 14040-901; ${ }^{2}$ Department of Genetics, Ribeirão Preto Medical School, University of São Paulo (USP), Ribeirão Preto, São Paulo 14049-900, Brazil
\end{abstract}

Received January 30, 2019; Accepted March 22, 2020

DOI: 10.3892/or.2020.7756

\begin{abstract}
Information on the mechanisms that are associated with tumor resistance has the potential to provide the fundamental basis for novel therapeutic strategies. In glioblastoma (GBM), predictive biomarkers of cellular responses to temozolomide (TMZ) combined with poly-ADP-ribose polymerase inhibitor (PARPi) remain largely unidentified. In this context, the influence of MGMT $\left(\mathrm{O}^{6}\right.$-methylguanine DNA methyltransferase) and PTEN (phosphatase and tensin homologue deleted on chromosome ten) has been studied in addition to the occurrence of synthetic lethality involving PTEN and PARPi. The present study investigated whether PARP-1 inhibition by NU1025 may increase the cytotoxicity of TMZ-induced lesions in GBM cells, and whether these mechanisms can be influenced by MGMT and PTEN status. The impact of PTEN deficiency in repair pathways, and the effects of PARP-1 inhibition and PTEN silencing, in terms of synthetic lethality, were also assessed. NU1025 combined with TMZ effectively sensitized TMZ-resistant cells (T98G PTEN-mutated and LN18 PTEN-wild-type) and TMZ-sensitive cells (U251MG PTEN-mutated), in contrast to NU1025 alone. However, the sensitizing effects were not observed in U87MG (PTEN-mutated) cells, suggesting that specific genetic alterations may influence the response to drug treatment. The sensitizing effects occurred independently of MGMT activity, which was evaluated in O6-BG-treated cells. PTEN silencing using small interfering (si)RNA did not sensitize PTEN-proficient cells to TMZ + NU1025, or
\end{abstract}

Correspondence to: Dr Elza T. Sakamoto-Hojo, Department of Biology, Faculty of Philosophy, Sciences and Letters at Ribeirão Preto, University of São Paulo, 3900 Bandeirantes Avenue, Ribeirão Preto, São Paulo 14040-901, Brazil

E-mail: etshojo@usp.br

Key words: PARP-1 inhibition, glioblastoma, temozolomide, PTEN, MGMT, predictive biomarker
NU1025 alone, indicating an absence of synthetic lethality. The responses to TMZ + NU1025 involved antiproliferative activity, G2/M arrest, double strand breaks and the induction of apoptosis. Following 20 days of recovery after three consecutive days of TMZ treatment, TMZ-resistant cells were observed. However, when TMZ was combined with NU1025, the viability of T98G and LN18 cells was extremely decreased, indicating a lethal drug combination. Therefore, independently of MGMT proficiency and PTEN status, TMZ combined with PARPi may be a promising strategy that can be used to overcome TMZ acquired resistance in GBM cells.

\section{Introduction}

Glioblastoma (GBM) is the most common and highly malignant glial tumor (Grade IV - World Health Organization). Complete surgical resection and adjuvant treatments (chemotherapy and radiotherapy) improve patient survival, but the prognosis for adult patients with GBM remains poor, with a median survival of 15-18 months (1-3). Temozolomide (TMZ) has been the most widely used drug treatment for patients with GBM (4), and $M G M T$ promoter methylation has been considered to be a predictor for chemotherapeutic response to alkylating and methylating agents $(5,6)$. However, there is a possibility that other DNA repair pathways may also promote GBM resistance to TMZ-induced base lesions (7). $\mathrm{N}^{7}$-methyl-guanine (N7-methyl-G) and $\mathrm{N}^{3}$-methyl-adenine (N3-methyl-A) adducts comprise $>80 \%$ of TMZ-induced DNA lesions and are processed through base excision repair (BER), which is a multiprotein mechanism that is initiated by several damage-specific glycosylases (8). Therefore, resistance to TMZ can be caused by an efficient repair process via BER (9-11), although other alternative processes may also occur.

Information on the mechanisms involved in tumor resistance has the potential to provide the fundamental basis for novel therapeutic strategies. In this context, an approach that has been extensively investigated is synthetic lethality, which may occur when two gene functions are compromised due to the simultaneous loss/or mutations in both genes, which can lead to cell death (12). Over two decades, this approach has 
been studied to explore the potential of applying PARP inhibition to cancer therapy (12-14), and the PARP-BRCA interaction provides the first successful example of clinical application in patients with breast/ovarian cancer (15-17). The increased susceptibility of breast cancer cells to PARP inhibitor (PARPi) is thought to result from the association between PARP-1, BER and homologous recombination (HR) repair pathways (17). Furthermore, the sensitivity to PARPi has also been reported in cells that present other genetic alterations affecting HR, including mutations in the phosphatase and tensin homologue deleted on chromosome ten (PTEN) gene (18) and ataxia telangiectasia mutated (ATM) deficiency (19). PTEN is a tumor-suppressor gene, which appears to play a role in astrocytomas (20). Changes in the PTEN gene, including the loss of heterozygosity, mutation and methylation, have been identified in at least $60 \%$ of GBMs (21). In addition to the phosphatase activity that is attributed to PTEN (22), it has been demonstrated that this protein is associated with the centromere, specifically interacting with the CENP-C region, becoming a critical controller of the dynamic organization of the centromere and promoting genomic stability. This can also lead to defects in double-strand break (DSB) repair when PTEN is absent, suggesting its role in the HR pathway (23). The authors of the aforementioned study also demonstrated that PTEN acts at the chromatin level, influencing the remodeling of the region encompassing the $R A D 51$ promoter, thereby controlling $R A D 51$ transcription by E2F-1. However, conflicting and limited results have been indicated regarding PTEN influence on the expression of RAD51 and its paralogs, as well as on HR efficiency (24). In glioma cells, it has previously been demonstrated that a disruption of HR components (RAD51 and $B R C A 2$ ) sensitizes these cells to alkylating agents, and it has been demonstrated that the inhibitor of PARP-1 (olaparib) increases cell death (25).

The genetic heterogeneity of GBM tumors is well recognized in the literature, but whether PTEN and MGMT status influence GBM response to treatment with TMZ combined with a PARP-1 inhibitor, has not yet been fully determined. The genetic changes present in tumor cells may contribute to drug sensitivity; therefore, it is relevant to investigate molecular signatures that represent potential predictive markers of susceptibility to therapies for patients with GBM.

The present study hypothesized that PARP-1 inhibition may increase the cytotoxicity of TMZ-induced lesions in GBM cells due to the role of the enzyme in damage responses and multiple DNA repair pathways. Therefore, the present study investigated whether these mechanisms can be influenced by MGMT and PTEN status. While it is well established that MGMT is the main factor that leads to GBM resistance to TMZ, the impact of PTEN deficiency in repair pathways, and the consequences of PARP-1 inhibition and PTEN silencing (or deficiency), in terms of synthetic lethality, was also evaluated in TMZ-treated GBM cells.

In the present study, GBM cell lines presenting different PTEN status and MGMT activity were used, and the results of combined treatments (TMZ plus PARPi - NU1025) were analyzed. The results demonstrated the effectiveness of these treatments in sensitizing TMZ-resistant and -sensitive cells, independent of MGMT activity. However, PARP-1 inhibition was unable to sensitize U87MG TMZ-sensitive cells, either as a single treatment, or in the TMZ-combined treatment. The cellular responses to TMZ/NU1025 in TMZ-resistant cells involved antiproliferative activity, G2/M arrest, DSBs and the induction of apoptosis. Regarding the influence of PTEN status on drug-treated cells, the results of the current study indicated that PTEN-silenced LN18 cells did not exhibit sensitization to PARPi tested alone, indicating an absence of synthetic lethality. Furthermore, the responses to the combined treatment (TMZ plus PARPi) were also independent of PTEN status. PARPi combined with TMZ treatment (during three days) caused a strong reduction in cell viability at 20 days, in contrast to cells treated with TMZ alone. Therefore, the combination of PARPi with TMZ was revealed to be a promising strategy that can be used to overcome TMZ-resistance in GBM cells, and these effects are independent of MGMT and PTEN.

\section{Materials and methods}

Cell lines and culture. T98G (CRL-1690; glioblastoma), LN18 (CRL-2610; glioblastoma) and U87MG (HTB-14 ${ }^{\mathrm{TM}}$; glioblastoma of unknown origin) cell lines were purchased from American Type Culture Collection, and U251MG (glioblastoma) was provided by Guido Lenz Department of Biophysics, Federal University of Rio Grande do Sul (UFRGS - Porto Alegre, RS, Brazil) (26). All cell lines were authenticated (STR profiling method) and evaluated for mycoplasma contamination prior to the experiments. The cell lines differ regarding the proficiency for the TP53 gene, and the activity of the MGMT repair enzyme (T98G and LN18 are TP53 deficient with high MGMT activity; U87MG is TP53 proficient and lacks MGMT activity; U251MG is TP53 deficient with no MGMT activity). T98G, U251MG and U87MG are PTEN-mutated but LN18 is PTEN wild-type $(27,28)$. T98G and LN18 cells, which are MGMT proficient, are resistant to $\mathrm{TMZ}$ treatment, indicating $\mathrm{IC}_{50}$ values $>500 \mu \mathrm{M}$, unlike U87MG and U251MG cells, which are sensitive $\left(\mathrm{IC}_{50}\right.$ values $<50 \mu \mathrm{M})(27)$. Therefore, T98G and LN18 are referred to as resistant cells, whereas $\mathrm{U} 87 \mathrm{MG}$ and $\mathrm{U} 251 \mathrm{MG}$ are referred to as sensitive to TMZ in the present study.

Cells were kept frozen in liquid nitrogen. After thawing, the cells were cultured in HAM F10/DMEM (1:1) medium (Sigma-Aldrich; Merck KGaA) supplemented with $10 \%$ FBS (Sigma-Aldrich; Merck KGaA), penicillin (100 U/ml; Sigma-Aldrich; Merck KGaA), and streptomycin (100 mg/ml; Sigma-Aldrich; Merck $\mathrm{KGaA}$ ) at $37^{\circ} \mathrm{C}$ in a humidified $5 \% \mathrm{CO}_{2}$ incubator.

\section{Cell treatment with TMZ and PARP-1 inhibitor. For TMZ} treatment (TEMODAL- Shering-Plough Corp.), the concentrations used in the present study were based on previous results $(9,27)$; those selected were above the values of $\mathrm{IC}_{50}$ calculated for the cell lines, although previous reports show that concentrations of $10-25 \mu \mathrm{M}$ are equivalent to those found in the spinal fluid of patients after treatment $(29,30)$. Therefore, TMZ-resistant cells (T98G and LN18; MGMT-proficient) were treated with 100 and $200 \mu \mathrm{M}$ of TMZ, while TMZ-sensitive cells (U87MG and U251MG; MGMT-deficient) were treated with $10 \mu \mathrm{M}$.

For PARP-1 inhibition, the NU1025 agent (Sigma-Aldrich; Merck KGaA) was used in the current study, since it has been 
successfully used by several authors (31-35). Two concentrations of NU1025 (NU-100 and $200 \mu \mathrm{M}$ ) were added $20 \mathrm{~min}$ prior to TMZ treatment. MGMT inhibition was achieved using $30 \mu \mathrm{M}$ of O6-BG inhibitor (Sigma-Aldrich; Merck KGaA) $1 \mathrm{~h}$ prior to TMZ treatment. All drugs remained in cell cultures until subsequent experimentation. To test the PARP-1 inhibition efficiency by NU1025 agent, the cells were treated with $\mathrm{H}_{2} \mathrm{O}_{2}(20 \mathrm{mM})$ for $10 \mathrm{~min}$ following NU1025 incubation, and were subsequently evaluated using immunofluorescent detection for poly-ADP-ribose (PAR) polymers.

Small interfering (si)RNA transfection. LN18 cells were transfected with PTEN siRNA (cat. no. sc-29459; Santa Cruz Biotechnology, Inc.) and a non-specific siRNA control (cat. no. sc-37007; Santa Cruz Biotechnology, Inc.) at a final concentration of $100 \mathrm{nM}$ with Lipofectamine 2000 (Invitrogen; Thermo Fisher Scientific, Inc.), according to the manufacturer's protocol. A control siRNA was used as a negative control, consisting of a scrambled sequence (20-25 nucleotides) that does not target any known genes in the target cells. The efficiency of LN18 siRNA transfected cells was confirmed using western blot analysis. Treatment with NU1025 and TMZ was performed $72 \mathrm{~h}$ after transfection, and the experiments were repeated three times.

Protein isolation and western blot analysis. Cells were lysed in $200 \mu \mathrm{l}$ of the RIPA buffer reagent (Thermo Fisher Scientific, Inc.) supplemented with Halt ${ }^{\mathrm{TM}}$ Protease Inhibitor Cocktail kit (Thermo Fisher Scientific, Inc.). Protein concentration was determined using BCA Protein Assay reagents (Thermo Fisher Scientific, Inc.), according to the manufacturer's protocol. Proteins $(30 \mu \mathrm{g})$ were separated by electrophoresis in NuPAGE 4-12\% Bis-Tris gel (Thermo Fisher Scientific, Inc.) and blotted onto a PVDF membrane (Thermo Fisher Scientific, Inc.). Samples were incubated in blocking buffer before the addition of the primary antibody. The immuno-detection was accomplished using a WesternBreeze Chemiluminescent kit (Thermo Fisher Scientific, Inc.). The antibodies used were as follows: anti-mouse PTEN (cat. no. 9556; dilution 1:1,000), anti-rabbit phospho-AKT ${ }^{\text {(ser473) }}$ (cat. no. 9271; dilution 1:500), anti-rabbit AKT (cat. no. 9272; dilution 1:1,000), anti-rabbit MGMT (cat. no. 2739; dilution 1:1,000), and anti-rabbit $\beta$-actin (cat. no. 4967; dilution 1:2,000) or anti-rabbit $\beta$-tubulin (cat. no. 2146; dilution 1:1,000), which were used as endogenous controls for normalization. All antibodies were purchased from Cell Signaling Technology, Inc. The chemiluminescence detection was performed using the ImageQuant LAS 500 (GE Healthcare Life Sciences) and quantified using Gel-Pro Analyzer 4.0 software (Media Cybernetics, Inc).

Cell proliferation assay. GBM cells (T98G, LN18, U87MG and $\mathrm{U} 251 \mathrm{MG})$ were seeded $(2,000$ cells/well) in 12 -well plates and incubated at $37^{\circ} \mathrm{C}$. After $24 \mathrm{~h}$, cells were treated with TMZ and NU1025, and cell viability was evaluated after 7 days. Cells were subsequently washed with PBS followed by incubation with XTT reagent kit as recommended by the manufacturer's protocol (Roche Molecular Diagnostics).

Clonogenic assay. A clonogenic assay was performed according to Franken et al (36). After seeding triplicates of
T98G and LN18 cells in 6-well plates (1,000 cells/well), drug treatments were performed. Approximately 10 days after treatment, cells were washed in PBS, fixed (methanol) and stained with Giemsa (20 min at room temperature). The colonies with $>50$ cells were counted using a stereomicroscope at $16 x$ magnification (Carl Zeiss).

Cell cycle analysis. After TMZ and NU1025 treatment, T98G and LN18 cells were washed with PBS and fixed in 70\% ethanol, stained for $15 \mathrm{~min}\left(37^{\circ} \mathrm{C}\right)$ with a solution containing propidium iodide (PI) $(5 \mu \mathrm{g} / \mathrm{ml})$ and RNase $(50 \mu \mathrm{g} / \mathrm{ml})$ and analyzed in a Guava EasyCyte Mini System (Merck KGaA), according to the manufacturer's protocol. Percentages of cells undergoing G0/G1, S, or G2/M phase were collected on days one and three after treatment and analyzed using Guava Personal Cell Analysis system (Merck KGaA).

Apoptosis assays and Annexin-V staining. Apoptosis detection was evaluated at 3 and 5 days following TMZ and NU1025 treatment. Apoptosis induction was measured using the Guava Nexin reagent (Merck KGaA), according to manufacturer's protocol. The samples were processed using flow cytometry and analyzed using Guava Personal Cell Analysis system (Merck KGaA).

Flow cytometry for $\gamma H 2 A X$ and PAR analysis. For $\gamma \mathrm{H} 2 \mathrm{AX}$ and PAR (poly-ADP-ribose) immunostaining, cells were fixed with paraformaldehyde (3\%) and permeabilized (Triton-X $0.5 \%$ ). Cells were then incubated with either primary rabbit monoclonal antibody to $\gamma \mathrm{H}_{2} \mathrm{AX}^{\text {(Ser-139) }}{ }^{\text {(cat. no. sc101696; Santa }}$ Cruz Biotechnology, Inc.), or anti-mouse pADPr (product code ab14459; Abcam), both diluted (1:400) and incubated for $1 \mathrm{~h}$ at $37^{\circ} \mathrm{C}$. Cells were then incubated with Alexa Fluor ${ }^{\circledR} 488$ anti-rabbit IgG (cat. no. A21441; Invitrogen; Thermo Fisher Scientific, Inc.) or Alexa Fluor ${ }^{\circledR} 594$ anti-mouse IgG (cat. no. A21201; Invitrogen; Thermo Fisher Scientific, Inc.; dilution 1:400) for $30 \mathrm{~min}$ at $37^{\circ} \mathrm{C}$. The percentage of positive cells was calculated using the Guava Personal Cell Analysis system (Merck KGaA).

$R N A$ isolation and reverse transcription-quantitative (RT-q) $P C R$ by PCR array. The transcriptional profiles were analyzed for a set of DNA repair genes and evaluated using RT-qPCR with a customized TaqMan ${ }^{\circledR}$ Assay Mix (Applied Biosystems; Thermo Fisher Scientific, Inc.). Cells were collected at 6 and $24 \mathrm{~h}$ post-treatment, and total RNA was isolated using illustra RNAspin Mini (GE Healthcare). RNA integrity was performed using a RNA 6000 Nano kit (Agilent Technologies, Inc.) and Bioanalyzer 2100 (Agilent Technologies, Inc.), following the manufacturer's protocol. The first-strand complementary DNA (cDNA) was synthesized from $1 \mu \mathrm{g}$ of each RNA sample using the SuperScript ${ }^{\circledR}$ VILO $^{\text {TM }}$ Master Mix (Invitrogen; Thermo Fisher Scientific, Inc.) according to the manufacturer's protocol. A cDNA pool of three independent experiments was used for the screening of gene expression profiles. The reactions were prepared using TaqMan ${ }^{\circledR}$ Fast Universal PCR Master Mix (Applied Biosystems). The TaqMan ${ }^{\circledR}$ Assay plate used was customized by Thermo Fisher Scientific, Inc., and contained 21 genes (DNA repair pathways) and two reference genes (Table SI). All plates were run on QuantStudio 3 

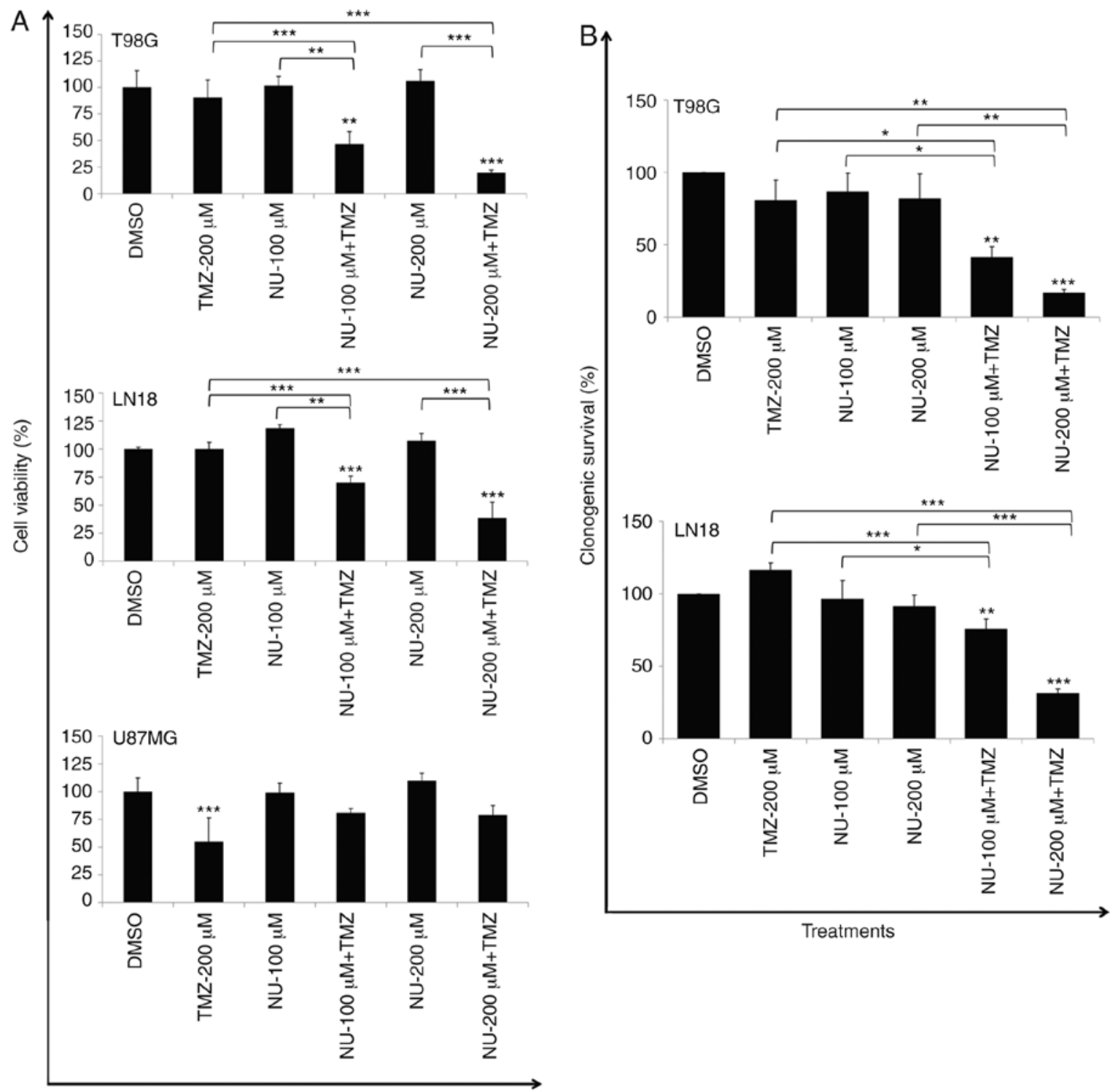

Treatments

Figure 1. Cytotoxic effects of TMZ and PARPi combined treatments. (A) Cell viability of T98G, LN18 and U87MG cells was evaluated by the XTT assay, after 7 days of NU1025 (NU-100 and NU-200 $\mu \mathrm{M}$ ) and TMZ (200 $\mu \mathrm{M}$ for T98 and LN18; $10 \mu \mathrm{M}$ for U87MG) continuous treatment. (B) Clonogenic survival of T98G and LN18 cells analyzed after 10 days of drug treatments. Values are mean \pm SD of three independent experiments. Statistical significance compared to control cells (DMSO). ${ }^{*} \mathrm{P}<0.05,{ }^{* *} \mathrm{P}<0.01,{ }^{* * * *} \mathrm{P}<0.001$. Bars correspond to the comparisons between treatments. TMZ, temozolomide; PARPi, poly-ADP-ribose polymerase inhibitor.

Real-Time PCR Systems (Applied Biosystems) and analyzed using QuantStudio ${ }^{\mathrm{TM}}$ Design \& Analysis Software1.3.1 (Applied Biosystems) using the $2^{-\triangle \Delta C q}$ method (37). TBP and HPRTl genes were used as endogenous controls.

Statistical analysis. Statistical analysis was performed using the SigmaStat software (version 3.5; Jandel Scientific Software). A one-way ANOVA, followed by Holm-Sidak multiple comparison tests, was used to establish whether significant differences existed between the groups. $\mathrm{P}<0.05$ was considered to indicate a statistically significant difference. All experiments were independently performed at least three times and the results are expressed as the mean \pm standard deviation. Results obtained for gene expression (cDNA pool of three independent experiments) are expressed as fold-change values.

\section{Results}

PARPi potentiates TMZ-induced cytotoxicity in GBM TMZ-resistant cell lines. To confirm specific genetic alterations in each cell line, MGMT, PTEN, and AKT protein expression was analyzed (Fig. S1A). Additionally, the $\mathrm{p}^{(\mathrm{ser} 473)}$ AKT was evaluated to confirm its activation due to PTEN deficiency in T98G and U87MG cells. To validate PARP-1 inhibition by NU1025, T98G cells were treated with $\mathrm{H}_{2} \mathrm{O}_{2}(20 \mathrm{mM})$ prior to NU1025 treatment (100 or $200 \mu \mathrm{M})$, and PAR levels were assessed using flow cytometry. Following a $10 \mathrm{~min}$ incubation, a significant increase in PARP-1 activity (PAR detection) was detected in $\mathrm{H}_{2} \mathrm{O}_{2}$-treated cells, while as expected, NU1025 treatment markedly decreased PAR polymers in response to $\mathrm{H}_{2} \mathrm{O}_{2}$ treatment (Fig. S1B). Cells were then treated with TMZ $(200 \mu \mathrm{M})$ and NU1025 $(100$ or $200 \mu \mathrm{M})$. As detected using a 

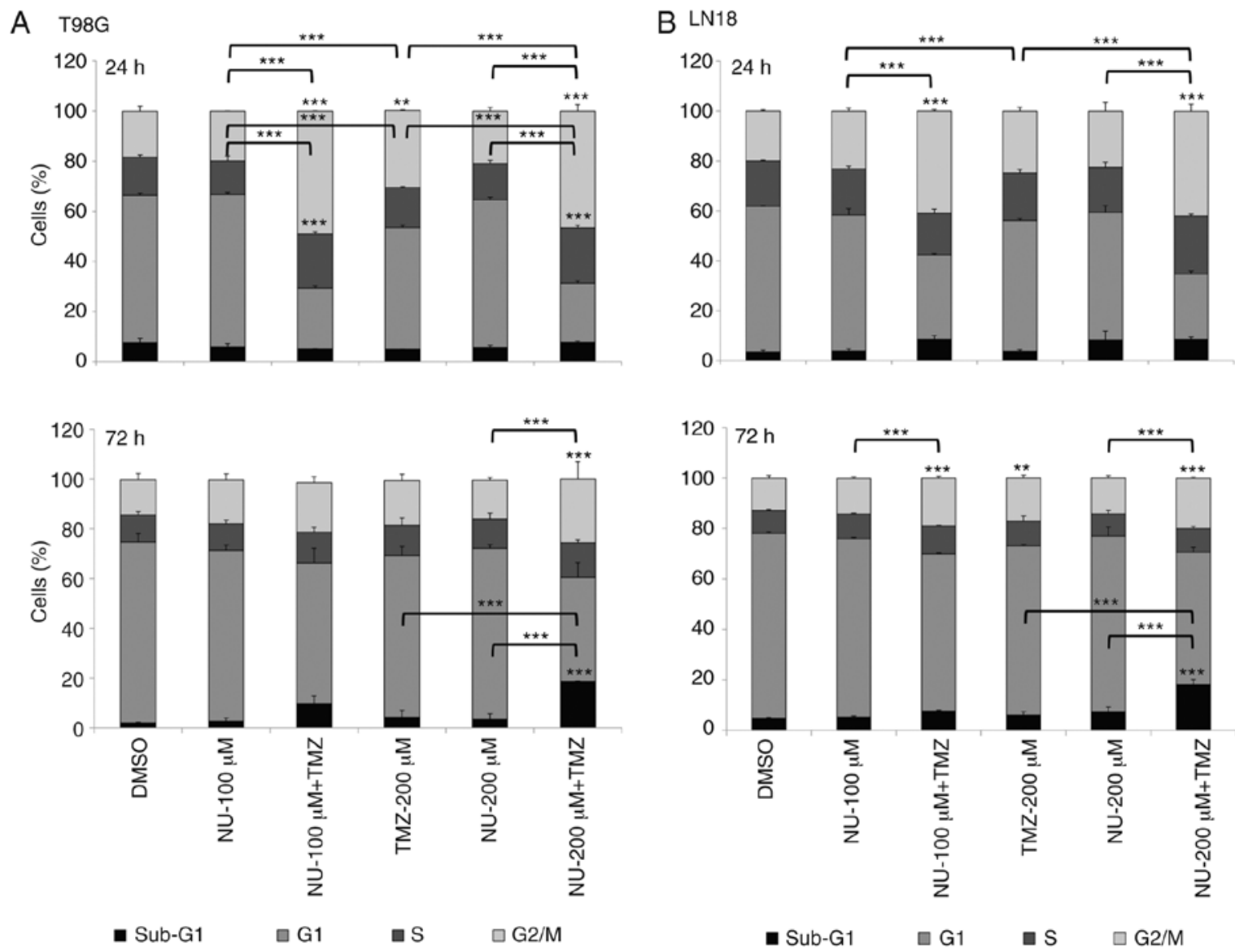

Figure 2. Cell cycle progression of GBM cells after TMZ and PARPi combined treatments. T98G (A) and (B) LN18 cells were treated with NU1025 (NU-100 and NU-200 $\mu \mathrm{M})$ and TMZ $(200 \mu \mathrm{M})$ and cell cycle kinetics was analyzed by flow cytometry after 24 and $72 \mathrm{~h}$ of treatments. Values are mean \pm SD of three independent experiments. Statistical significance compared to control cells (DMSO). ${ }^{* *} \mathrm{P}<0.01,{ }^{* * *} \mathrm{P}<0.001$. Bars correspond to the comparisons between treatments. GBM, glioblastoma; TMZ, temozolomide; PARPi, poly-ADP-ribose polymerase inhibitor.

XTT assay, which was performed after 7 days of continuous treatment, the drug combination caused a significant reduction in cell viability in T98G (PTEN-mutated) and LN18 cells (PTEN-wild type), which are TMZ-resistant (MGMT proficient cells), and this was independent to the PTEN status (Fig. 1A). Survival rates were reduced $\sim 4.7$ - and 3.7-fold following the combined treatment (NU-200 $\mu \mathrm{M}+\mathrm{TMZ}-200 \mu \mathrm{M})$ for T98G and LN18 cells, respectively, compared with a TMZ single treatment, as evaluated at 10 days after treatment (Fig. 1B). Similar experiments were performed in TMZ-sensitive U87MG cells (PTEN-mutated), which did not present MGMT, to analyze their sensitivity to the combined treatment. A marked reduction in cell viability was observed in cells treated with TMZ $(10 \mu \mathrm{M}$, single treatment), and a significant difference was not indicated between TMZ alone and TMZ combined to NU1025 (Fig. 1A).

NU1025 (single treatment) did not demonstrate a cytotoxic effect in PTEN proficient (LN18) and deficient cells (T98G and U87MG), indicating that PTEN status may not contribute to the synthetic lethality promoted by PARPi in the absence of DNA damage, which is induced by TMZ in GBM cells.

Combined treatment of PARPi and TMZ induces G2/M blockage and apoptosis. It has been previously reported that BER intervention by APE1 depletion in T98G cells caused $\mathrm{G} 2 / \mathrm{M}$ arrest, DSBs and apoptosis induction in response to TMZ treatment (10). The present study investigated whether the inhibition of PARP-1 could cause similar effects considering its role in the BER pathway. Whether differences in the PTEN status could lead to different drug responses was therefore assessed. T98G and LN18 cells treated with TMZ $(200 \mu \mathrm{M})$ plus NU1025 (100 or $200 \mu \mathrm{M})$ indicated a significant $\mathrm{G} 2 / \mathrm{M}$ block at $24 \mathrm{~h}$ after treatment compared with single-treatments (TMZ or NU1025) and control (DMSO) cells. G2/M arrest was maintained after $72 \mathrm{~h}$, compared with NU1025-treated and control cells, either in T98G (NU-200 $\mu \mathrm{M}+\mathrm{TMZ})$ and LN18 cells (NU-100 or $200 \mu \mathrm{M}+\mathrm{TMZ}$ ). Furthermore, only T98G cells treated with NU1025 + TMZ also demonstrated a significant increase in the proportion of S-phase cells observed at $24 \mathrm{~h}$, compared with single-treatments and the control. T98G and LN18 cell lines also revealed a significant increase in the sub-G1 content (DNA fragmentation) following treatment with TMZ plus NU1025 $(200 \mu \mathrm{M})$ in cells collected after $72 \mathrm{~h}$, compared with single drug-treatments or the control group (Fig. 2A and B). The cell cycle blockade may have occurred as a result of DSBs generated by the combined treatment, as evaluated by the detection of $\gamma \mathrm{H} 2 \mathrm{AX}$-positive cells (6, 24 and $72 \mathrm{~h})$, which were demonstrated to be increased. In these experiments, $\gamma \mathrm{H} 2 \mathrm{AX}$-positive cells were calculated (average of relative values), as the experimental vs. the control (DMSO), in order to compare the responses between cell lines, taking into account their genetic background, including the PTEN status. The results indicated that DSB induction was 


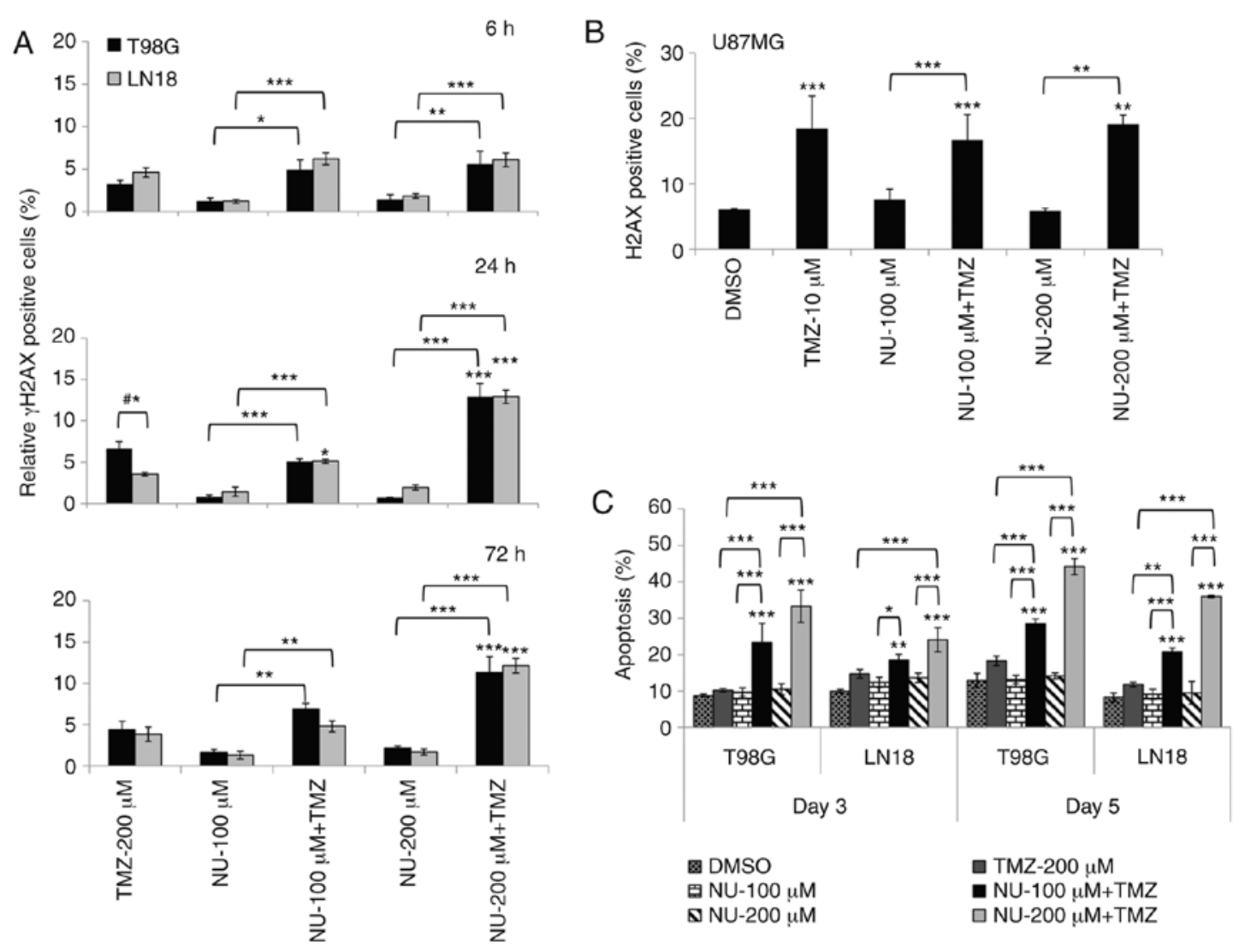

Figure 3. Combined treatments (TMZ and PARPi) induce DSBs and apoptotic cell death. (A) Percentages of $\gamma \mathrm{H} 2 \mathrm{AX}$-positive staining in T98G and LN18 cells after 6, 24 and $72 \mathrm{~h}$ of TMZ $(200 \mu \mathrm{M})$ and NU1025 (NU-100 and NU-200 $\mu \mathrm{M})$ treatment, as analyzed by flow cytometry. (B) Percentages of U87MG $\gamma \mathrm{H} 2 \mathrm{AX}$-positive cells after 3 days of TMZ $(10 \mu \mathrm{M})$ and NU1025 (NU-100 and NU-200 $\mu \mathrm{M})$ treatment, analyzed by flow cytometry. (C) Apoptosis induction in T98G and LN18 cells after 3 and 5 days of TMZ $(200 \mu \mathrm{M})$ and NU1025 (NU-100 and NU-200 $\mu \mathrm{M}$ ) treatment analyzed by flow cytometry using Annexin-V reagent. Values are mean $\pm \mathrm{SD}$ of three independent experiments. Statistical significance compared to control cells (DMSO). ${ }^{*} \mathrm{P}<0.05,{ }^{* * *} \mathrm{P}<0.01,{ }^{* * * *} \mathrm{P}<0.001$. Bars correspond to the comparisons among treatments. (\#*) correspond to the comparison between cell lines. DSBs, double-strand breaks; TMZ, temozolomide; PARPi, poly-ADP-ribose polymerase inhibitor.

similar in both cell lines (T98G and LN18), except for TMZ single treatment in $\mathrm{T} 98 \mathrm{G}$ cells, which presented a greater percentage of $\gamma \mathrm{H} 2 \mathrm{AX}$-positive cells detected at $24 \mathrm{~h}$ (Fig. 3A). These data indicated that differences in the PTEN status did not significantly affect the induction of DSBs. The amount of $\gamma \mathrm{H} 2 \mathrm{AX}$-positive cells increased from 6 to $72 \mathrm{~h}$ following the combined treatments, and the reduction in cell viability may be a consequence of a decreased DNA repair that is promoted by PARP inhibition. In U87MG cells, the $\gamma \mathrm{H} 2 \mathrm{AX}$ induction (Fig. 3B) was likely due to the TMZ single-treatment, confirming the lack of response to the combined treatment, as demonstrated by the results of the cell viability assay.

Furthermore, the results of the present study indicated that the responses to DNA damage observed for the combined treatment was different when comparing the two cell lines, since $\mathrm{T} 98 \mathrm{G}$ indicated higher levels of apoptosis induction than LN18 cells. This may be due to LN18 being more efficient in DSB repair than T98G cells (Fig. 3C). NU1025 single treatment did not induce changes in the cell cycle kinetics, and did not cause any effect on the induction of DSBs and apoptosis, corroborating the results of cell viability and clonogenic survival.
PTEN in the HR pathway (18), experiments were performed in LN18 PTEN-silenced cells to demonstrate the lack of synthetic lethality, since this phenomenon was not observed in PTEN-deficient cells (T98G, U251, and U87MG). siRNA PTEN LN18 cells indicated a substantial decrease in gene expression (94.7\% of knockdown; data not shown), as well as in PTEN protein level (Fig. 4A and B). The total-AKT expression was not significantly affected by the PTEN silencing, but an increase in $\mathrm{p}$-AKT expression was observed (Fig. 4C and D). This indicates that PTEN downregulation promotes the modulation of the PI3K/AKT signaling pathway, and this is supported by the increase in the p-AKT/total-AKT ratio in PTEN-silenced cells (Fig. 4D). However, in these cells, PTEN downregulation did not significantly influence the responses to PARPi tested as a single agent, and in a combination with TMZ, compared with siSCR cells (transfection control), as evaluated using cell viability (Fig. 4E) and Annexin assays (Fig. 4F). These results indicated that PTEN does not contribute to the occurrence of synthetic lethality in GBM cells, and is not crucial for the cytotoxicity induced by the combined treatment (TMZ + NU1025) in LN18 TMZ-resistant cells.

MGMT repair does not influence the efficiency of PARPi plus TMZ treatment. To evaluate whether the effects of TMZ 
A

C

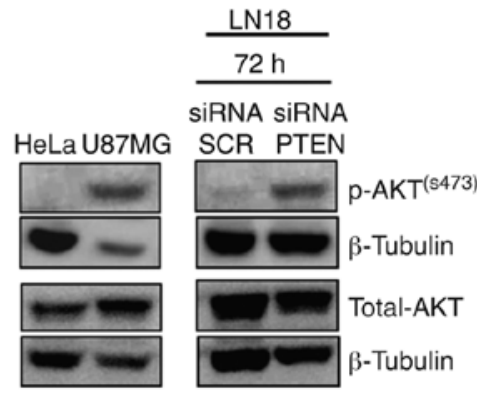

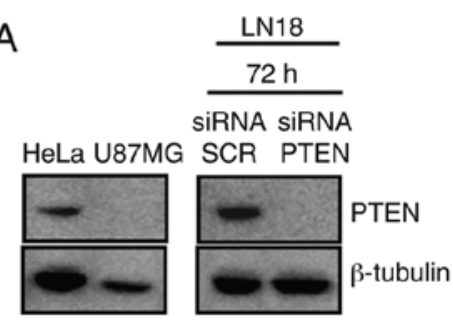

B
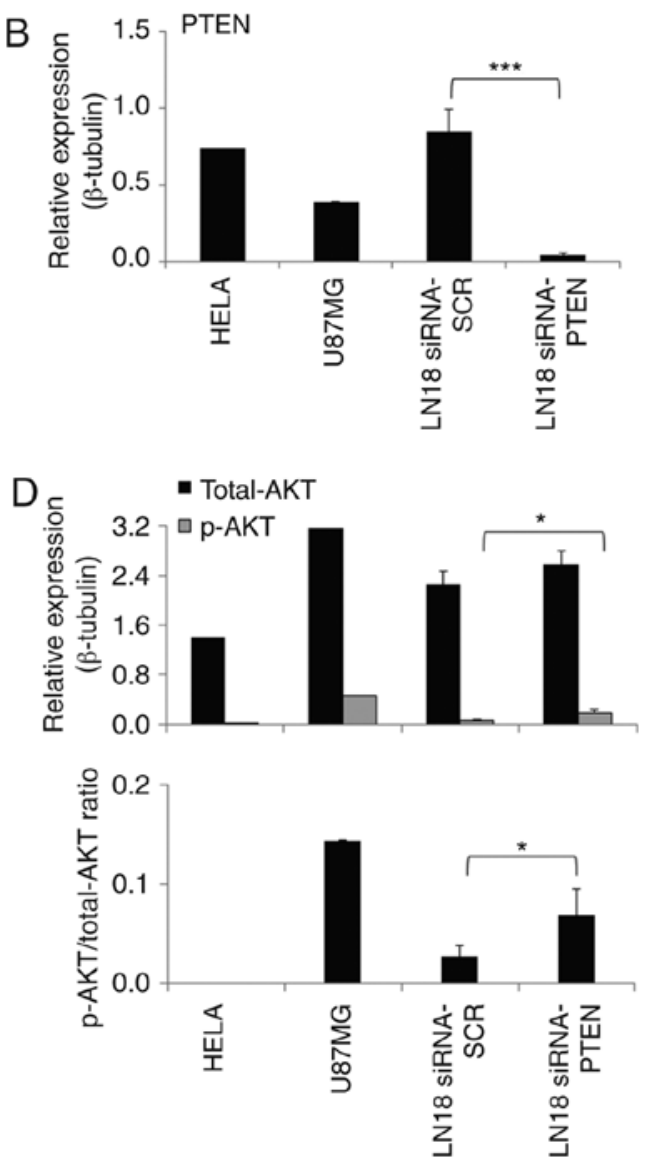

E

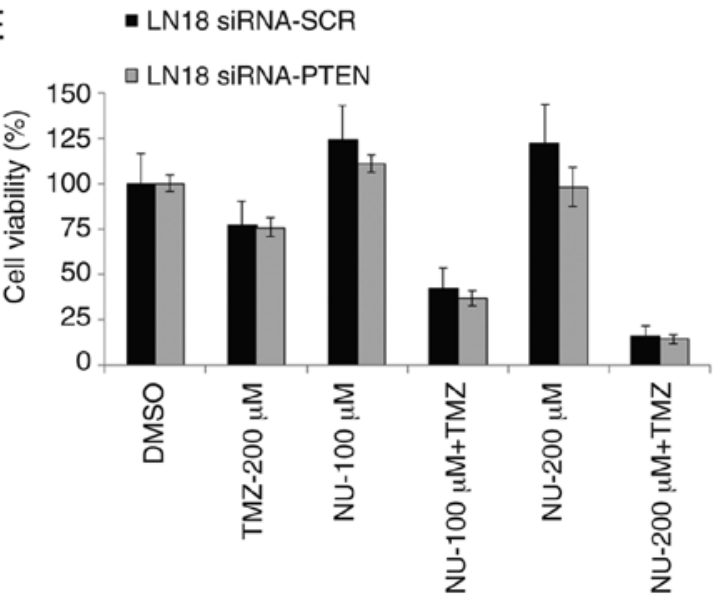

$\mathrm{F}$

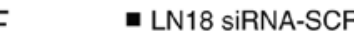

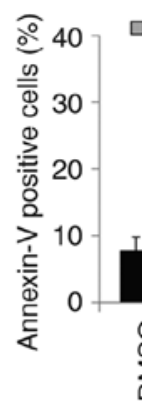

口 LN18 SIRNA-PTEN

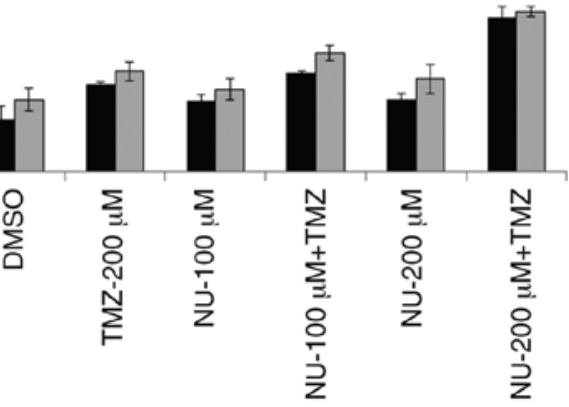

Figure 4. Cellular responses of LN18 PTEN-silenced cells to combined treatments. (A) PTEN expression and (B) quantification by western blot analysis after $72 \mathrm{~h}$ of transfection with SCR (control) or PTEN siRNA. (C) p-AKT and total-AKT expression and (D) quantification, as well as p-AKT/total AKT ratio, following $72 \mathrm{~h}$ of transfection. U87MG and HeLa cells were used as negative and positive controls for PTEN expression, respectively. $\beta$-tubulin was used as a loading control. (E) Cell viability of LN18 SCR or PTEN siRNA cells treated with TMZ (200 $\mu$ M) and NU1025 (U-100 and U-200 $\mu$ M) analyzed at 7 days after continuous drug treatment, as measured by the XTT assay. (F) Flow cytometric analysis of Annnexin-V positive staining in LN18 PTEN and SCR silenced cells, analyzed at 3 days after TMZ $(200 \mu \mathrm{M})$ and NU1025 (U-100 and U-200 $\mu$ M) treatment. Values are mean \pm SD calculated from three independent experiments. Statistical significance: ${ }^{*} \mathrm{P}<0.05,{ }^{* * *} \mathrm{P}<0.001$. Bars correspond to comparisons between treatments. PTEN, phosphatase and tensin homologue deleted on chromosome ten.

plus NU1025 combined treatment are dependent on MGMT activity, the O6-BG agent was used to inhibit the activity of the enzyme in T98G and LN18 cells. A significant reduction in cell viability was observed in the TMZ/O6-BG and TMZ/O6-BG/NU (100 and $200 \mu \mathrm{M})$ treated cells. The results indicated that the inhibition of MGMT activity (O6-BG) did not significantly counteract the effectiveness of PARP inhibi- tion in TMZ-treated cells, since it also contributed to a possible additive effect on cell sensitization (Fig. 5A). Additionally, to test whether MGMT repair influenced the response to PARPi plus TMZ treatment, experiments were performed in U251MG cells, which are deficient for MGMT activity (27), and also carry TP53 and PTEN mutations (28). The results obtained for U251MG cells revealed that MGMT activity does not 

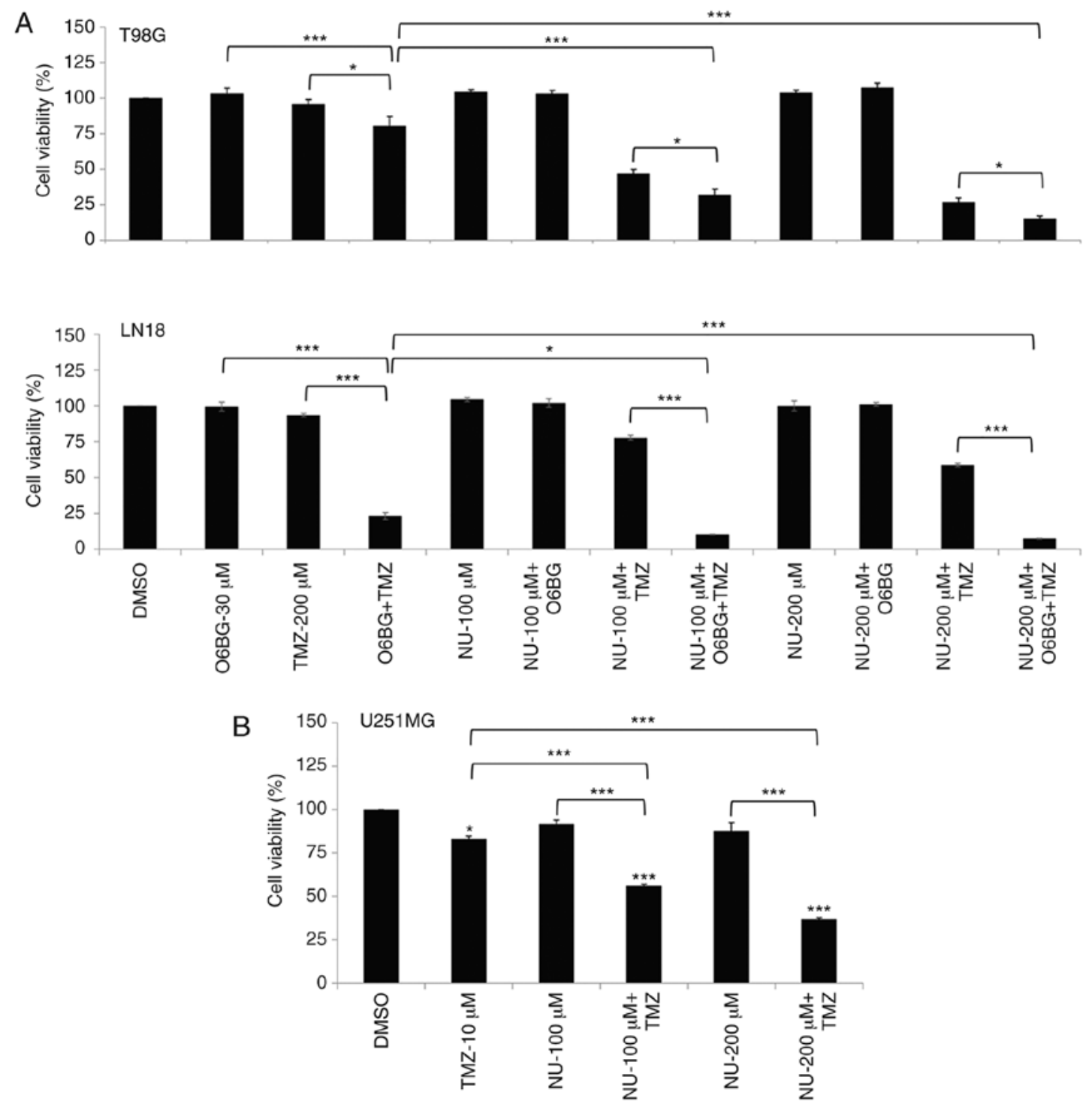

Figure 5. NU1025 enhances the cytotoxic effects of TMZ treatment independently of MGMT activity and does not cause acquired resistance. (A) Cell viability of T98G and LN18 cells after MGMT inhibition (O6-BG agent, $30 \mu \mathrm{M})$ and continuous treatment with TMZ $(200 \mu \mathrm{M})$ and NU1025 agents (NU-100 and NU-200 $\mu \mathrm{M})$. (B) U251MG viable cells treated with TMZ $(10 \mu \mathrm{M})$ and NU1025 (NU-100 and NU-200 $\mu \mathrm{M})$. The cell viability was evaluated by the XTT assay, after 7 days following treatments. Statistical significance compared to control cells (DMSO). ${ }^{*} \mathrm{P}<0.05,{ }^{* * *} \mathrm{P}<0.001$. Bars correspond to comparisons between treatments. TMZ, temozolomide; MGMT, $\mathrm{O}^{6}$-methylguanine DNA methyltransferase.

affect cellular responses to drug treatments, and corroborated the results obtained in T98G and LN18 cells under MGMT inhibition (Fig. 5B). However, the absence of a response observed for U87MG cells suggested the influence of other genetic alteration, since these cells also lack MGMT activity.

PARPi treatment overcomes TMZ-induced resistance. Cell viability was also determined following 20 days of recovery time after three consecutive days of TMZ (100 and $200 \mu \mathrm{M})$ treatment, administered alone or in combination with NU1025 $(200 \mu \mathrm{M})$, to evaluate the occurrence of resistance to the combined treatment. TMZ treatment was unable to reduce cell viability following 20 days. However, a period of three consecutive days of combined treatment (TMZ plus NU-200 $\mu \mathrm{M}$ ) was efficient to significantly decrease the viability in T98G and LN18 cell lines (Fig. 6), demonstrating the absence of resistance under the conditions tested, and indicating that the induced-lethality was independent to the PTEN status. Taken together, these results demonstrated the effectiveness of the drug combination to sensitize TMZ-resistant tumor cells.

Transcript expression of GBM cells exposed to TMZ plus PARPi treatment. To determine the influence of the PARP-1 inhibitor on the recruitment of repair mechanisms in response to TMZ treatment, a gene set of DNA repair genes was selected to evaluate transcriptional expression profiles $(6$ and $24 \mathrm{~h})$ in LN18 and T98G cell lines. BER (APEX1, PARP1, FEN1, LIG1, and $X R C C 1)$, HR (BRCA1, RAD51, RAD51B/C/D and $L I G 4)$, non-homologous end joining (NHEJ; $P R K D C$ and $X R C C 5 / 6$ ), nucleotide excision repair (NER; $X P A, X P C$, and $X R C C 4$ ), mismatch repair (MMR; $M S H 2 / 3$ ) and $M G M T$ genes were evaluated in the current study. In addition, transcriptional expression of HR genes was compared between the two cell lines, which possess a different PTEN status. To establish differential transcript expression, fold-change ( $\log 2)$ values $>11.3$ I were considered to be the cut off. 


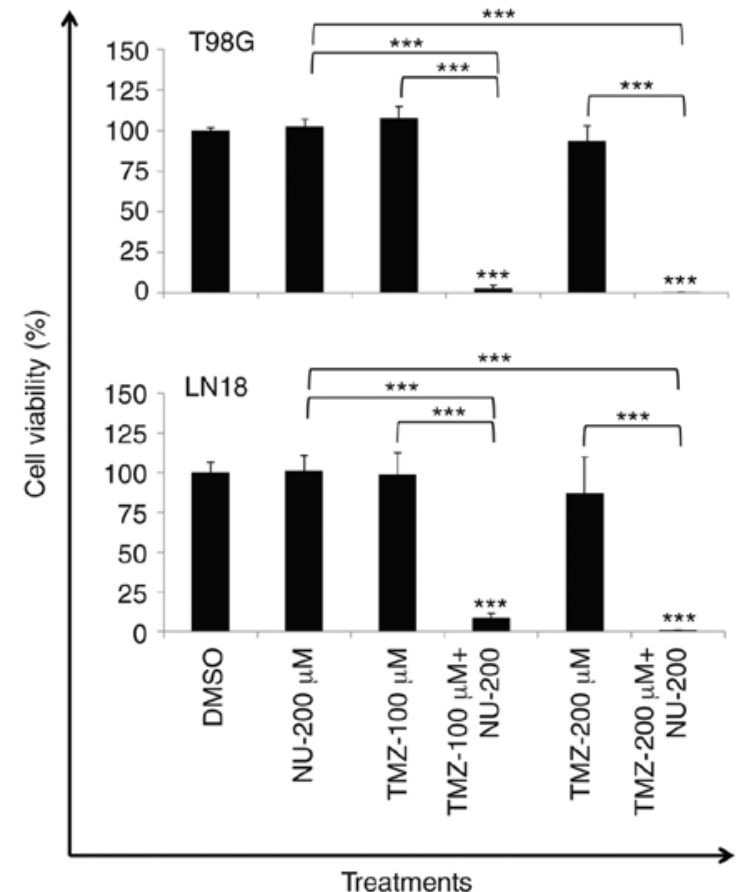

Figure 6. Combined treatment of NU1025 and TMZ does not cause acquired resistance. T98G and $\mathrm{LN} 18$ viable cells in response to 3 days of combined or single treatments of TMZ (100 and $200 \mu \mathrm{M}$ ) and NU1025 (NU-200 $\mu \mathrm{M}$ ), following 20 days recovery, evaluated by the XTT assay. Values are mean \pm SD calculated from results of three independent experiments. ${ }^{* * *} \mathrm{P}<0.001$. Bars correspond to comparisons between treatments. TMZ, temozolomide.

In the clustering analysis, the two cell lines presented a distinct damage response, however, each cell line was clustered according to the time-point ( 6 or $24 \mathrm{~h}$ ), except for T98G NU1025-treated cells evaluated after $24 \mathrm{~h}$ (Fig. 7). Regarding DNA repair pathways in T98G PTEN-deficient cells, BER (PARPI, FENI, and LIGI) and HR (BRCAl and RAD5IB/C) genes were indicated to be slightly induced by TMZ ( $24 \mathrm{~h})$, while the effect of PARP-1 inhibition by NU1025 abolished these responses in the combined treatment (Fig. 7; Table SII). However, LN18 PTEN-proficient cells did not exhibit changes in expression in response to treatments (Fig. 7; Table SIII). An upregulation of $R A D 51$ paralogs ( $B$ and $C$ ) was indicated following a single treatment of TMZ in T98G $P T E N$-deficient cells, but the same result was not revealed in LN18 PTEN-proficient cells, indicating that there is no correlation between PTEN status and the expression of these genes, which are associated with the HR pathway.

\section{Discussion}

Despite a number of studies concerning the use of poly-ADP-ribose polymerase inhibitors (PARPi) as a strategy for cancer treatment (38-40), information on the mechanisms and genetic factors influencing the responses to PARPi and temozolomide (TMZ) combination are still largely undetermined, especially in glioblastoma (GBM). To study this approach and the mechanisms associated with drug responses, four cell lines that present different genetic alterations regarding MGMT activity and PTEN genes were analyzed in the current study.

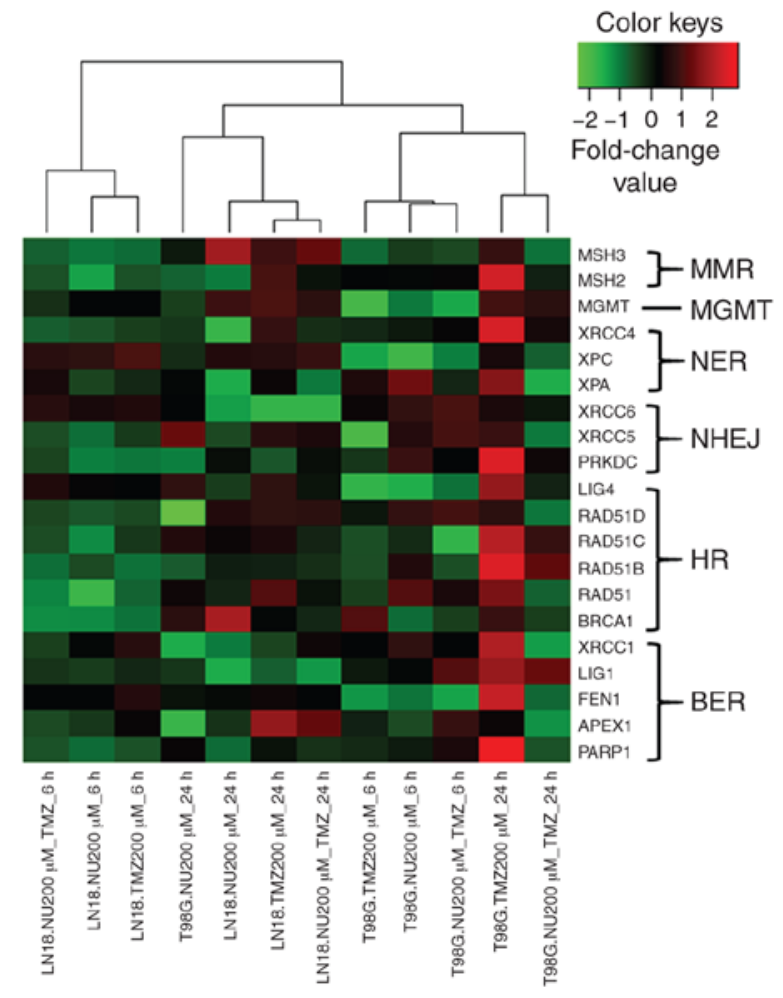

Figure 7. GBM cell lines showing gene expression profiles in response to PARPi and TMZ combination. Hierarchical clustering illustrating a graphical representation of transcript expression profiles for a gene set encompassing the major repair pathways (BER, NER, MGMT, MMR, HR and NHEJ), as analyzed in LN18 and T98G cells treated with TMZ $(200 \mu \mathrm{M})$ and NU1025 $(200 \mu \mathrm{M})$ for 6 and $24 \mathrm{~h}$. The genes and samples were grouped by using Pearson's correlation, according to the similarity of expression level. Upregulated and downregulated genes are represented in red and green colors, respectively; black represents a lack of differential expression. Variations in the color intensity represent different levels of transcript expression. GBM, glioblastoma; TMZ, temozolomide; BER, base excision repair; NER, nucleotide excision repair; MGMT, $\mathrm{O}^{6}$-methylguanine DNA methyltransferase; MMR, mismatch repair; HR, homologous recombination; NHEJ, non-homologous end joining.

The results indicated that the combined treatment (TMZ plus NU1025) was effective in reducing the cell viability and clonogenic survival rates presented by TMZ-resistant cells (T98G and LN18, which are MGMT-proficient). The potentiating effects of the TMZ + PARPi combination treatment occurred independently to MGMT activity, as observed in U251MG TMZ-sensitive (MGMT-deficient) and MGMT-inhibited cells (T98G and LN18 cell lines). The drug combination caused a $\mathrm{G} 2 / \mathrm{M}$ arrest due to the generation of double-strand breaks (DSBs) (possibly via the conversion of $\mathrm{N}$-methylpurine lesions, which were not removed due to repair intervention by PARPi), leading to the induction of apoptosis in T98G and LN18 cells. In these cells, increased amount of unrepaired DNA damage was caused by the inhibition of PARP-1 by NU1025, leading to cell death following drug treatments.

However, these responses were not observed in TMZ-sensitive U87MG cells, in which MGMT enzyme activity is absent, in contrast to the results reported by Tentori et al (41), using another PARPi (GPI 15427). In the present study, the decrease observed in cell viability in U87MG cells occurred as a consequence of TMZ-induced DSBs in the combined treatments. Erice et al (42), demon- 
strated that MGMT-proficient melanoma cells, strongly responded to the combination of TMZ and PARPi. For GBM, a number of studies have reported conflicting results regarding markers of response to PARP inhibitors combined with TMZ, including MGMT, PARP-1 or PTEN expression (41-44), emphasizing the importance of these studies regarding the influence of genetic alterations in drug responses. LN18 (PTEN-proficient) and T98G (PTEN-mutant) cells present high MGMT activity, demonstrating high resistance to TMZ, even at concentrations of $100-200 \mu \mathrm{M}$, and they were sensitized only by the combined treatment. On the other hand, U87MG and U251MG cells (MGMT-deficient; PTEN-mutant) were more sensitive to TMZ $(10 \mu \mathrm{M})$, and none of them were affected by PARPi tested alone. However, only U251MG cells were sensitized upon the combined treatment. Thus, regardless of TMZ concentration, PTEN-deficient cells presented different responses to the TMZ and PARPi combined treatment. The current results in U87MG cells suggest a possible influence of additional genetic alterations, since MGMT activity and the PTEN status did not interfere in the efficiency of the combined treatment (PARPi + TMZ). Alterations in TP53 may also cause impact on drug responses and may distinguish these cells (U87MG is wild-type while T98G, LN18 and U251MG are mutant for this gene). It has been demonstrated that radiation-induced changes in transcript profiles of GBM cell lines are dependent on the functional status of TP53 (45). It has also been reported that TP53 influences the differential sensitivity of GBM cell lines to combined treatments, including topoisomerase I inhibitor topotecan, radiation therapy, and PARPi (such as NU1025) (35). Zaky et al (46) revealed that TP53 regulated APE1 transcriptional expression in colorectal adenocarcinoma tumor cells, which was also supported by a study performed by Poletto and colleagues (47) in normal and transformed human fibroblasts. In a previous study, the impact of APE1 gene silencing was assessed in terms of the TMZ response, and while U87MG cells did not exhibit sensitization to TMZ treatment, T98G was significantly sensitized by APE1 downregulation (10). It has been indicated that APE1/CHK2 signaling is associated with the coordination of DSB repair, facilitating homologous recombination (HR); however, where there is low APE1 expression, non-homologous end joining (NHEJ) becomes the prevalent repair pathway (48). The authors showed that U87MG cells presented a low basal APE1 protein expression, and on the basis of this information (48), it can be suggested that the error-prone NHEJ might be a predominant repair pathway in these cells, explaining the lack of responses to PARP-1 inhibition in the present study. Therefore, when studying different cell lines, determining the genetic background of each GBM cell line is critical to understand the responses to PARP-1 inhibition.

In the present study, the influence of PTEN status was studied in T98G (PTEN-mutated) and LN18 (PTEN-wild type) cell lines, and these cells presented similar responses regarding $\mathrm{G} 2 / \mathrm{M}$ blockade and DSB induction caused by the combined treatments, regardless of the PTEN status and AKT activation. T98G cells (PTEN-deficient) demonstrated a reduction in cell viability and induction of apoptosis that were slightly more pronounced than LN18 cells
(PTEN-proficient) in response to the combined treatment, suggesting some survival pathway or differential damage tolerance between the cell lines, which may have been due to different inherent genetic alterations in these tumor cells. PTEN has been a subject of controversial studies regarding its role in HR efficiency (24). Thus, PTEN knockdown experiments by siRNA were conducted to confirm whether the lack of this gene function could contribute to the occurrence of synthetic lethality, or interfere in the combined treatment, considering the possible involvement of PTEN in the HR pathway (18). PTEN gene silencing in LN18 did not modify the cellular responses in terms of viability and apoptosis induction, suggesting that this gene did not cause any impact in the responses of the two cell lines to the NU1025 single- or combined treatment (TMZ + NU1025), although the relevance of PTEN roles had been recognized regarding its participation in the PI3K-AKT signaling pathway, and regulation of the $\mathrm{G} 2 / \mathrm{M}$ checkpoint, which is associated with genomic instability in tumor cells $(49,50)$. Conflicting conclusions have been reported regarding the role of PTEN in drug responses. This may be due to the fact that cancer cells, which have been developed within the context of a genotype with a PTEN mutation, accumulate secondary genetic aberrations, differing from cells in which PTEN has been experimentally removed $(24,51)$. This may explain the responses to drug treatments that are observed in PTEN-silenced LN18 cells.

The transcript expression profiles of a gene set, whose genes represent the major repair pathways (BER, NER, MGMT, MMR, HR and NHEJ), were also examined, since multiple DNA repair pathways can affect the cellular sensitivity to damage caused by methylating agents $(52,53)$. The results revealed that following a 24-h treatment (after one cell doubling), T98G cells treated with TMZ exhibited a number of upregulated genes, including PARP1, FEN1 and LIGl (BER), BRCA1, RAD51B/C (HR), PRKDC (NHEJ) and $X R C C 4$ (NER), while most genes were downregulated or unmodulated at $6 \mathrm{~h}$ after treatment. LN18 cells did not exhibit changes in expression profiles for the whole gene set. In other studies, the expression of HR genes (BRCAl, $B R C A 2, R A D 51$ and $F A N C D 2$ ) were also markedly increased in $\mathrm{U} 251 \mathrm{MG}$ and A172 cells at $48 \mathrm{~h}$ after TMZ treatment, but only BRCAl was induced in U87MG cells, suggesting a more effective DNA repair capacity in U251MG and A172 than U87MG cells (54). The expression of RAD51 and its paralogs did not change in LN18 PTEN-proficient cells, which was different to the effect in T98G PTEN-deficient cells, which presented an upregulation of $R A D 51 B / C$. In a previous study, U251MG cells (PTEN-mutated) exposed to ionizing radiation (IR) indicated RAD51 foci, suggesting a functional HR (48). This finding indicated a negligible PTEN influence on RAD51 transcript expression in GBM cells. These results also revealed that cell responses to TMZ treatment may differ among cell lines depending on their genetic background. Furthermore, for transcript gene expression, the hierarchical cluster indicated that the cell lines with differences in PTEN status (T98G and LN18) were grouped separately, according to time-point (6 or $24 \mathrm{~h}$ ). These observations reinforce the relevance of the genetic background inherent to each cell line and indicated that cell 
responses to drug treatment cannot be driven by a single genetic alteration, including PTEN status.

Regarding the PARPi effect on gene expression profiles, NU1025 was effective in inducing a downregulation of the majority of genes in TMZ-treated T98G cells. Since PARP-1 and PARylation serve an important role in the orchestration of the early steps of DNA damage responses, damage signaling and cross-talk with DNA repair pathways $(52,55,56)$, the alterations in transcript expression may be associated with the slight sensitization achieved in T98G cells in response to the combined treatment (TMZ + NU1025), compared with LN18 cells.

In the present study, the survival rates following 20 days (recovery time following cell treatment with TMZ plus PARPi along 3 consecutive days) were close to zero in both cell lines, strongly indicating the efficiency of PARP-1 inhibition in cell death, regardless of PTEN status. PARPi in TMZ-treated cells may act to avoid the activation of DNA repair mechanisms, which, as suggested by Ströbel et al (48) and Nagel et al (57), can lead to an adaptive response to TMZ.

In conclusion, the present study highlights the therapeutic potential of PARPi and TMZ combination for GBM treatment, demonstrating that TMZ-resistant GBM cells, due to the high MGMT activity (known as the main predictor of TMZ response in GBM), can be sensitized by the combination of PARPi with TMZ treatment. The results revealed that PTEN gene status and MGMT activity are not genetic predictive markers for the responses to TMZ/PARPi combination in GBM, even though the results with U87MG TMZ-sensitive cells, which were not sensitized to the combined treatment, suggest that other genetic alterations (inherent to the genetic background) may influence the success of the combined treatment. Additionally, PTEN did not influence the expression of HR genes, and its downregulation or deficiency did not sensitize GBM cells to the PARPi single-treatment used in the present study, indicating an absence of synthetic lethality.

\section{Acknowledgements}

The authors are indebted to Mr Luiz A. Costa Jr. for the technical assistance, and Natalia C.S. Moreira for helping with the identification of the cell lines. Our special gratitude to Professor Dr Aguinaldo L. Simões and Mrs Maria do Carmo T. Canas for performing authentication of the GBM cell lines.

\section{Funding}

We acknowledge the financial support from São Paulo Research Foundation (FAPESP, Brazil, grant nos: 2013/12033-0, 2016/17862-3 and 2013/09352-7), National Council for Scientific and Technological Development (CNPq, Brazil) and Coordination for the Improvement of Higher Education Personnel (CAPES, Brazil).

\section{Availability of data and materials}

The datasets used during the present study are available from the corresponding author upon reasonable request.

\section{Authors' contributions}

APM carried out the experimental design, performance of the experiments and analyses of all samples, interpreted the data and wrote the manuscript; SCGL assisted in various experiments. PRDVG participated in the experimental design, data interpretation and revised the manuscript. DJX conducted the qPCR array experiments and data analysis. ETSH supervised the research work and experimental design, participated in the data collection and interpretation and manuscript preparation. All authors read and approved the manuscript and agree to be accountable for all aspects of the research in ensuring that the accuracy or integrity of any part of the work are appropriately investigated and resolved.

\section{Ethics approval and consent to participate}

Not applicable.

\section{Patient consent for publication}

Not applicable.

\section{Authors' information}

Elza Tiemi Sakamoto-Hojo, ORCID: 0000-0002-1383-3314.

\section{Competing interests}

The authors declare that they have no competing interests.

\section{References}

1. Ostrom QT, Gittleman H, Fulop J, Liu M, Blanda R, Kromer C, Wolinsky Y, Kruchko C and Barnholtz-Sloan JS: CBTRUS statistical report: Primary brain and central nervous system tumors diagnosed in the united states in 2008-2012. Neuro Oncol 17 (Suppl 4): iv1-iv62, 2015.

2. Thakkar JP, Dolecek TA, Horbinski C, Ostrom QT, Lightner DD Barnholtz-Sloan JS and Villano JL: Epidemiologic and molecular prognostic review of glioblastoma. Cancer Epidemiol Biomarkers Prev 23: 1985-1996, 2014.

3. Wick W, Osswald M, Wick A and Winkler F: Treatment of glioblastoma in adults. Ther Adv Neurol Disorder 11: 1756286418790452, 2018

4. Dresemann G: Temozolomide in malignant glioma. OncoTargets Ther 3: 139-146, 2010.

5. Mutter N and Stupp R: Temozolomide: A milestone in neuro-oncology and beyond? Expert Rev Anticancer Ther 6: 1187-1204, 2006

6. Cabrini G, Fabbri E, Lo Nigro C, Dechecchi MC and Gambari R: Regulation of expression of $\mathrm{O}^{6}$-methylguanine-DNA methyltransferase and the treatment of glioblastoma (Review). Int J Oncol 47: 417-428, 2015.

7. Yoshimoto K, Mizoguchi M, Hata N, Murata H, Hatae R, Amano T, Nakamizo A and Sasaki T: Complex DNA repair pathways as possible therapeutic targets to overcome temozolomide resistance in glioblastoma. Front Oncol 2: 186, 2012.

8. Wallace SS, Murphy DL and Sweasy JB: Base excision repair and cancer. Cancer Lett 327: 73-89, 2012.

9. Montaldi AP and Sakamoto-Hojo ET: Methoxyamine sensitizes the resistant glioblastoma T98G cell line to the alkylating agent temozolomide. Clin Exp Med 13: 279-288, 2013.

10. Montaldi AP, Godoy PR and Sakamoto-Hojo ET: APE1/REF-1 down-regulation enhances the cytotoxic effects of temozolomide in a resistant glioblastoma cell line. Mutat Res Genet Toxicol Environ Mutagen 793: 19-29, 2015.

11. Liu L and Gerson SL: Therapeutic impact of methoxyamine: Blocking repair of abasic sites in the base excision repair pathway. Curr Opin Investig Drugs 5: 623-627, 2004. 
12. Lord CJ, Tutt AN and Ashworth A: Synthetic lethality and cancer therapy: Lessons learned from the development of PARP inhibitors. Annu Rev Med 66: 455-470, 2015.

13. Hartwell LH, Szankasi P, Roberts CJ, Murray AW and Friend SH: Integrating genetic approaches into the discovery of anticancer drugs. Science 278: 1064-1068, 1997.

14. Bhattacharjee $S$ and Nandi S: DNA damage response and cancer therapeutics through the lens of the fanconi anemia DNA repair pathway: Cell Commun Signal 15: 41, 2017.

15. Bryant HE, Schultz N, Thomas HD, Parker KM, Flower D, Lopez E, Kyle S, Meuth M, Curtin NJ and Helleday T: Specific killing of BRCA2-deficient tumours with inhibitors of poly(ADP-ribose) polymerase. Nature 434: 913-917, 2005.

16. Farmer H, McCabe N, Lord CJ, Tutt AN, Johnson DA, Richardson TB, Santarosa M, Dillon KJ, Hickson I, Knights C, et al: Targeting the DNA repair defect in BRCA mutant cells as a therapeutic strategy. Nature 434: 917-921, 2005

17. Helleday T: The underlying mechanism for the PARP and BRCA synthetic lethality: Clearing up the misunderstandings. Mol Oncol 5: 387-393, 2011.

18. Mendes-Pereira AM, Martin SA, Brough R, McCarthy A, Taylor JR, Kim JS, Waldman T, Lord CJ and Ashworth A: Synthetic lethal targeting of PTEN mutant cells with PARP inhibitors. EMBO Mol Med 1: 315-322, 2009.

19. Weston VJ, Oldreive CE, Skowronska A, Oscier DG, Pratt G, Dyer MJ, Smith G, Powell JE, Rudzki Z, Kearns P, et al: The PARP inhibitor olaparib induces significant killing of ATM-deficient lymphoid tumor cells in vitro and in vivo. Blood 116: 4578-4587, 2010.

20. Ohgaki $\mathrm{H}$ and Kleihues P: Genetic pathways to primary and secondary glioblastoma. Am J Pathol 170: 1445-1453, 2007.

21. Verhaak RG, Hoadley KA, Purdom E, Wang V, Qi Y, Wilkerson MD, Miller CR, Ding L, Golub T, Mesirov JP, et al: Cancer genome atlas research network: Integrated genomic analysis identifies clinically relevant subtypes of glioblastoma characterized by abnormalities in PDGFRA, IDH1, EGFR, and NF1. Cancer Cell 17: 98-110, 2010.

22. Salmena L, Carracedo A and Pandolfi PP: Tenets of PTEN tumor suppression. Cell 133: 403-414, 2008.

23. Shen WH, Balajee AS, Wang J, Wu H, Eng C, Pandolfi PP and Yin Y: Essential role for nuclear PTEN in maintaining chromosomal integrity. Cell 128: 157-170, 2007.

24. Lester A, Rapkins R, Nixdorf S, Khasraw M and McDonald K: Combining PARP inhibitors with radiation therapy for the treatment of glioblastoma: Is PTEN predictive of response? Clin Transl Oncol 19: 273-278, 2016.

25. Quiros S, Roos WP and Kaina B: Rad51 and BRCA2-New molecular targets for sensitizing glioma cells to alkylating anticancer drugs. PLoS One 6: e27183, 2011.

26. Filippi-Chiela EC, Thomé MP, Bueno e Silva MM, Pelegrini AL Ledur PF, Garicochea B, Zamin LL and Lenz G: Resveratrol abrogates the temozolomide-induced G2 arrest leading to mitotic catastrophe and reinforces the temozolomide-induced senescence in glioma cells. BMC Cancer 13: 147, 2013.

27. Hermisson M, Klumpp A, Wick W, Wischhusen J, Nagel G, Roos W, Kaina B and Weller M: O6-methylguanine DNA methyltransferase and p53 status predict temozolomide sensitivity in human malignant glioma cells. J Neurochem 96: 766-776, 2006.

28. Ishii N, Maier D, Merlo A, Tada M, Sawamura Y, Diserens AC and Van Meir EG: Frequent co-alterations of TP53, p16/CDKN2A p14ARF, PTEN tumor suppressor genes in human glioma cell lines. Brain Pathol 9: 469-479, 1999.

29. Ostermann S, Csajka C, Buclin T, Leyvraz S, Lejeune F, Decosterd LA and Stupp R: Plasma and cerebrospinal fluid population pharmacokinetics of temozolomide in malignant glioma patients. Clin Cancer Res 10: 3728-3736, 2004.

30. Patel M, McCully C, Godwin K and Balis FM: Plasma and cerebrospinal fluid pharmacokinetics of intravenous temozolomide in non-human primates. J Neurooncol 61: 203-207, 2003

31. Cimmino G, Pepe S, Laus G, Chianese M, Prece D, Penitente R and Quesada P: Poly(ADPR)polymerase-1 signalling of the DNA damage induced by DNA topoisomerase I poison in D54(p53wt) and U251(p53mut) glioblastoma cell lines. Pharmacol Res 55: 49-56, 2007.

32. Sabisz M, Wesierska-Gadek J and Skladanowski A: Increased cytotoxicity of an unusual DNA topoisomerase II inhibitor compound C-1305 toward HeLa cells with downregulated PARP-1 activity results from re-activation of the p53 pathway and modulation of mitotic checkpoints. Biochem Pharmacol 79 1387-1397, 2010.
33. Zhang J, Stevens MF, Laughton CA, Madhusudan S and Bradshaw TD: Acquired resistance to temozolomide in glioma cell lines: Molecular mechanisms and potential translational applications. Oncology 78: 103-114, 2010.

34. Cieślar-Pobuda A, Saenko Y and Rzeszowska-Wolny J: PARP-1 inhibition induces a late increase in the level of reactive oxygen species in cells after ionizing radiation. Mutat Res 732: 9-15, 2012.

35. Sabbatino F, Fusciello C, Somma D, Pacelli R, Poudel R, Pepin D, Leonardi A, Carlomagno C, Della Vittoria Scarpati G, Ferrone S and Pepe S: Effect of p53 activity on the sensitivity of human glioblastoma cells to PARP-1 inhibitor in combination with topoisomerase I inhibitor or radiation. Cytometry A 85 : 953-961, 2014

36. Franken NA, Rodermond HM, Stap J, Haveman J and van Bree C: Clonogenic assay of cells in vitro. Nat Protoc 1: 2315-2319, 2006.

37. Livak KJ and Schmittgen TD: Analysis of relative gene expression data using real-time quantitative PCR and the 2(-Delta Delta C(T)) method. Methods 25: 402-408, 2001

38. Atkins RJ, Ng W, Stylli SS, Hovens CM and Kaye AH Repair mechanisms help glioblastoma resist treatment. J Clin Neurosci 22: 14-20, 2015.

39. Sandhu SK, Yap TA and de Bono JS: Poly(ADP-ribose) polymerase inhibitors in cancer treatment: A clinical perspective. Eur J Cancer 46: 9-20, 2010.

40. Majuelos-Melguizo J, Rodríguez MI, López-Jiménez L, Rodríguez-Vargas JM, Martí Martín-Consuegra JM, Serrano-Sáenz S, Gavard J, de Almodóvar JM and Oliver FJ: PARP targeting counteracts gliomagenesis through induction of mitotic catastrophe and aggravation of deficiency in homologous recombination in PTEN-mutant glioma. Oncotarget 6 : 4790-4803, 2015.

41. Tentori L, Ricci-Vitiani L, Muzi A, Ciccarone F, Pelacchi F, Calabrese R, Runci D, Pallini R, Caiafa P and Graziani G: Pharmacological inhibition of poly(ADP-ribose) polymerase-1 modulates resistance of human glioblastoma stem cells to temozolomide. BMC Cancer 14: 151, 2014.

42. Erice O, Smith MP, White R, Goicoechea I, Barriuso J, Jones C, Margison GP, Acosta JC, Wellbrock C and Arozarena I: MGMT expression predicts PARP-mediated resistance to temozolomide. Mol Cancer Ther 14: 1236-1246, 2015.

43. Gupta A, Yang Q, Pandita RK, Hunt CR, Xiang T, Misri S, Zeng S, Pagan J, Jeffery J, Puc J, et al: Cell cycle checkpoint defects contribute to genomic instability in PTEN deficient cells independent of DNA DSB repair. Cell Cycle 8: 2198-2210, 2009.

44. Balvers RK, Lamfers ML, Kloezeman JJ, Kleijn A Berghauser Pont LM, Dirven CM and Leenstra S: ABT-888 enhances cytotoxic effects of temozolomide independent of MGMT status in serum free cultured glioma cells. J Trans Med 13: 74, 2015.

45. Godoy PR, Mello SS, Magalhães DA, Donaires FS, Nicolucci P, Donadi EA, Passos GA and Sakamoto-Hojo ET: Ionizing radiation-induced gene expression changes in TP53 proficient and deficient glioblastoma cell lines. Mutat Res 756: 46-55, 2013.

46. Zaky A, Busso C, Izumi T, Chattopadhyay R, Bassiouny A, Mitra S and Bhakat KK: Regulation of the human AP-endonuclease (APE1/Ref-1) expression by the tumor suppressor p53 in response to DNA damage. Nucleic Acids Res 36: 1555-1566, 2008

47. Poletto M, Legrand AJ, Fletcher SC and Dianov GL: P53 coordinates base excision repair to prevent genomic instability. Nucleic Acids Res 44: 3165-3175, 2016.

48. Ströbel T, Madlener S, Tuna S, Vose S, Lagerweij T, Wurdinger T, Vierlinger K, Wöhrer A, Price BD, Demple B, et al: Apel guides DNA repair pathway choice that is associated with drug tolerance in glioblastoma. Sci Rep 7: 9674, 2017.

49. Ming $M$ and He YY: PTEN in DNA damage repair. Cancer Lett 319: 125-129, 2012.

50. Mukherjee A and Karmakar P: Attenuation of PTEN perturbs genomic stability via activation of Akt and down-regulation of Rad51 in human embryonic kidney cells. Mol Carcinog 52: 611-618, 2013.

51. Hunt CR, Gupta A, Horikoshi N and Pandita TK: Does PTEN loss impair DNA double-strand break repair by homologous recombination? Clin Cancer Res 18: 920-922, 2012.

52. Fu D, Calvo JA and Samson LD: Balancing repair and tolerance of DNA damage caused by alkylating agents. Nat Rev Cancer 12 : 104-120, 2012.

53. Schuhwerk H, Atteya R, Siniuk K and Wang ZQ: PARPing for balance in the homeostasis of poly(ADP-ribosyl)ation. Semin Cell Dev Biol 63: 81-91, 2017 
54. Chai KM, Wang CY, Liaw HJ, Fang KM, Yang CS and Tzeng SF: Downregulation of BRCA1-BRCA2-containing complex subunit 3 sensitizes glioma cells to temozolomide. Oncotarget 5: 10901-10915, 2014.

55. Ray Chaudhuri A and Nussenzweig A: The multifaceted roles of PARP1 in DNA repair and chromatin remodelling (Review). Nat Rev Mol Cell Biol 18: 610-621, 2017.
56. Polo SE and Jackson SP: Dynamics of DNA damage response proteins at DNA breaks: A focus on protein modifications. Genes Dev 25: 409-433, 2011.

57. Nagel ZD, Kitange GJ, Gupta SK, Joughin BA, Chaim IA, Mazzucato P, Lauffenburger DA, Sarkaria JN and Samson LD: DNA repair capacity in multiple pathways predicts chemoresistance in glioblastoma multiforme. Cancer Res 77: 198-206, 2017. 